\title{
The development of a health-related quality-of-life instrument for young people with narcolepsy: NARQoL-21
}

\author{
John E. Chaplin ${ }^{1 *}$, Attila Szakács ${ }^{1,2}$, Tove Hallböök ${ }^{1}$ and Niklas Darin ${ }^{1}$
}

\begin{abstract}
Background: Narcolepsy is a lifelong sleep disorder with a prevalence of between $0.03 \%$ and $0.06 \%$ and onset at around puberty. It is associated with psychiatric comorbidities and cognitive difficulties. No valid and reliable condition-specific health-related quality-of-life ( $\mathrm{HrQoL}$ ) instrument has been developed for this population.

Methods: A questionnaire based on four mixed-gender age-defined focus group discussions and a patient panel analysis was administered to young people with narcolepsy and a control group. External reliability was measured by a test-retest procedure and internal reliability was measured using Cronbach's alpha. Convergent validity with the KIDSCREEN-10 index was assessed using with intraclass correlation coefficients (ICC) and receiver operating characteristic (ROC) curves. Factor analysis techniques were used to identify suitable items and confirm the factor structure. Baseline values were assessed for convergent validity, ceiling effects, agreement and sensitivity. Comparison with KIDSCREEN-10 was made on the basis of area under the curve (AUC).

Results: One hundred young people with narcolepsy and 95 control subjects returned questionnaires. The factor structure revealed two main factors with five domains and 21 questions, which was confirmed with confirmatory factor analysis. The domains of the NARQoL-21 showed good independence while the floor and ceiling effects were acceptable. The external reliability (0.928), convergent validity $(r s=0.769)$ and internal consistency (Cronbach's alpha $=0$. 886) were excellent. A Bland-Altman plot revealed some proportional bias. Good discriminant validity was detected for control/patient (Cohen's $d=2.114)$. ROC analysis showed significantly better AUC for NARQoL-21 (0.939) than KIDSCREEN (0.877). A cut-off score equivalent to KIDSCREEN-10 for suboptimal HrQoL which maximized sensitivity (84\%) and specificity (92\%) was found at NARQOL-21 score below 42.

Conclusions: Establishing the validity of a disease-specific HrQoL instrument in a population of people with a rare condition poses significant challenges. The mixed-methods approach adopted here has resulted in a questionnaire of 21 items with good discrimination and convergent validity, and excellent internal and external reliability, allowing precise and stable measurements. The cut-off score can be useful to identify patients with very poor HrQoL and thus improve the design of treatment options. Further testing in a longitudinal cohort is recommended in order to establish responsiveness.
\end{abstract}

Keywords: Narcolepsy, Child, Adolescence, HrQoL, Focus groups, Factor analysis, Roc, Mixed methods

\footnotetext{
*Correspondence: john.chaplin@gu.se

'Department of Pediatrics, Institute of Clinical Sciences, Sahlgrenska

Academy at University of Gothenburg, Gothenburg, Sweden

Full list of author information is available at the end of the article
} 


\section{Background}

Narcolepsy is a rare chronic neurological condition characterized by daytime sleepiness with repeated lapses into sleep of short duration [1]. The symptoms can include cataplexy (sudden episodes of muscle weakness triggered by strong emotions), sleep paralysis, and hypnagogic or hypnopompic hallucinations [2]. Associated features such as automatic behavior [3] may also be present and disrupted nocturnal sleep occurs in more than $50 \%$ of cases [1].

Narcolepsy has a prevalence ranging between $0.03 \%$ and $0.067 \%[4,5]$ and a bimodal onset pattern with a large peak around puberty and a smaller peak around 35 to 45 years of age [6]. The disease is caused by deficiency of the sleep-wake regulating neuropeptide hypocretin-1 [7]. Narcolepsy has been associated with an increased prevalence of psychiatric comorbidity as well as cognitive difficulties $[8,9]$, which can lead to poor school performance $[10,11]$. Adult patients report substantially lower health-related quality of life (HrQoL) indicating potential long-term consequences [12, 13]. Impaired HrQoL has also been found in studies of children with narcolepsy [10, 14]. Condition-specific measures are more sensitive for the detection and quantification of small changes that are important to patients and clinicians [15]; however, no condition-specific instruments have been developed to measure HrQoL in children or adolescents with narcolepsy. Therefore, in order to assess the particular concerns of this group, a self-report disease-specific instrument was considered important.

The purpose of this study is to describe the development of a narcolepsy-specific HrQoL self-report questionnaire for children and adolescents from conceptual model development through instrument validation. In order to incorporate the patients' perspectives on the HrQoL outcomes that matter to them, a cooperative design process was used [16], which involved patient input via focus groups as well as patient participation in the design process via a patient panel.

\section{Methods}

\section{Focus groups and item extraction}

Four, age-defined (8-13 and 15-17 years), mixed-gender focus group interviews were carried out at the Queen Silvia Children's Hospital, Gothenburg, and at the Ågrenska, National Competence Center For Rare Diseases, Gothenburg during 2012-2013. All participants spoke Swedish as their first or second language. A standardized focus group methodology developed for the DISABKIDS QoL project was used [17], including a semi-structured interview schedule using a multi-stage method converging on specific QoL issues related to narcolepsy [18]. The four sessions were held over approximately $90 \mathrm{~min}$. All focus group discussions were digitally recorded and transcribed. Two additional focus groups were conducted with parents of these patients. A patient panel provided a thematic analysis of the statements, producing a set of themes which helped to identify important statements and reduce the number of items. Cognitive debriefing of the items further refined the statements. (See Focus Group Summary in Additional file 1.)

\section{Pilot study}

The pilot questionnaire was distributed to patients and the control group during 2013. The patient participants were approached via the Swedish Narcolepsy Association (Narkolepsiföreningen), via hospital outpatient clinics in the health care regions covering the west of Sweden, and via a narcolepsy closed-group Facebook page. The control group was drawn from pupils and students attending local schools.

\section{Instruments used in the study}

The KIDSCREEN-10 Mental Health Index was developed by means of a Rasch analysis, which ensured that only those items which represented a global, unidimensional latent trait were included. Rasch person parameters are assigned to each possible sum score, and transformed into values with a mean of 50 and standard deviation of 10 . The index provides good discriminatory power and strong internal consistency (Cronbach's alpha $=.82$ ) and test-retest reliability $(r=.73)$, allowing precise and stable measurements $[19,20]$. The cut-off at T-value below 38 (which represents the lowest 10\%) indicates higher risk for poor mental health [19]). All analyses are done with 10-item General HRQoL index international T-values based on RASCH person parameters. A Swedish language version of the index was developed and validated as part of the original KIDSCREEN project [19].

The NARQoL-21 is a HrQoL instrument for children and adolescents with narcolepsy, consisting of 21 questions in five domains. These are summarized into the three following measures: Psychosocial summary scale, Future outlook summary scale, and HrQoL scale. It is a child self-report instrument using a five-point Likert scale with responses ranging from completely untrue to completely true. The summated rating method is used for each domain and, for ease of interpretation, the raw scores are transformed to a $0-100$ scale, with higher scores indicating a positive HrQoL.

\section{Translation}

An English translation of the NARQoL-21 (See Additional file 2) was carried out through several steps: an initial forward translation (from Swedish to English) 
by two independent translators with a background in linguistics and quality of life research, a back translation (from English to Swedish), and finally a consensual version to check against the original NARQoL-21 by all three translators and the originator of the instrument. Discrepancies were discussed and agreement achieved.

\section{Psychometric testing}

Data were analyzed using IBM Corp. Released 2011. IBM SPSS Statistics for Windows, Version 20.0. Armonk, NY: IBM Corp. To test the external reliability of the questionnaire, a test-retest procedure was carried out with an interval of 2 weeks between questionnaire completion. Respondents were contacted via the Swedish Narcolepsy Association members who had completed the questionnaire. There was no preselection of respondents for participation in this stage. Internal reliability was assessed by Cronbach's alpha. A classical test theory approach was used to analyze the pilot test results and identify items for deletion. Floor and ceiling effects are considered to be present if more than 15\% of respondents achieve the lowers or highest possible score [21]. Means and SD of scores for matched patient and control groups are presented in order to enable interpretability of scores.

Both principal components and principal axis factor analyses with Promax rotation were undertaken. Three criteria were used to determine the number of factors: scree plot, eigenvalue, and percentage of variance explained by the factors. A threshold factor loading of 0.5 was chosen as a good indicator of sample-to-population pattern fit. The best-fitting model identified from the exploratory factor analysis was subsequently submitted for confirmatory factor analysis using IBM SPSS AMOS for Windows version 20.0.0.1. The overall model fit was assessed using the chi-square test statistic and alternative fit indices with the following cut-offs for acceptable fit: below 0.08 for the root mean squared error of approximation (RMSEA), above 0.90 for both the comparative fit index and the Tucker-Lewis index, while factor loadings should be above 0.40 [22].

\section{Missing data}

Complete case analysis (listwise deletion), was applied for analyses of the pilot test data. Cases were removed where missing data exceeded $10 \%$ and affected the analysis. The largest amount of missing data was due to the control group not completing both the NARQoL-21 and KIDSCREEN-10 questionnaires. Subjects not completing both questionnaires were excluded from control group comparisons thus resulting in different numbers at different points in the analysis.

\section{Reliability}

Item analyses included inspecting item means, medians, standard deviations, percentage ceiling and floor effects, item-to-total correlations, and Cronbach's alpha to determine internal consistency. A 2-week test-retest reliability test was posted to a subgroup of patients from the Swedish Narcolepsy Association. External reliability was assessed using an intraclass correlation coefficient (ICC) on a two-factor mixed-effects model [23] with 95\% confidence interval (CI). An ICC of at least 0.70 was considered to be satisfactory for group comparisons, whereas an ICC of at least 0.90 was considered to be satisfactory for individual comparisons [24].

\section{Construct validity}

Convergent validity was assessed by examining the association between KIDSCREEN-10 Mental Health Index and the new NARQoL-21 questionnaire at the scale level. In the comparison of generic and condition specific instruments and based on previous research, we hypothesized that the KIDSCREEN-10 would show moderate-to-strong positive correlation coefficients [19, 25]. We used the Spearman rank correlation (rs). However, we were interested in more than just correlation between the two measures and wished to measure the strength of the agreement between them [26]; therefore, we assessed the ICC and Bland-Altman plot [26]. The ICC was computed with a two-way random effects model based on absolute agreement and a coefficient above 0.7 as an indicator of strong agreement [27]. To visualize the agreement, we represented the data graphically in a Bland-Altman plot [26].

Known groups analysis was conducted by comparison between a patient group and a control group. These analyses detected significant differences in the median scores between the two groups (Mann-Whitney U test). The effect size, indicating the degree of differences between the groups, was calculated by dividing the Standardized Test statistic ( $\mathrm{z}$ ) by the square root of $\mathrm{N}$ (where $\mathrm{N}$ is the number of observations). According to Cohen [28], for independent samples, the degree of difference ( $\mathrm{d}$ value) of 0.20 is small, 0.50 is medium, and 0.80 is a large. Cohen's d was calculated with Becker Effect Size Calculator [29].

\section{Sensitivity of the NARQoL-21}

A receiver operating characteristic (ROC) analysis was conducted to describe the sensitivity and specificity of the NARQoL-21 compared to the criteria measure of KIDSCREEN-10. The area under the ROC curves (AUC) was computed to compare the discriminative properties of the two instruments [30]. The ROC method provides a useful overview of the relationship between a measure 
and an external indicator of health [31]. Thereby, the validity of the new questionnaire will be reflected by its ability to discriminate between healthy control subjects and patients with narcolepsy. A z-score test was used to compare the AUCs, and a value of $p<0.05$ (one-tailed test) was considered a significant difference [32].

\section{Results}

Content validity: Focus groups, patient panel, and cognitive debriefing

Children and adolescents with narcolepsy identified in the health care regions covering the west of Sweden participated in four focus groups. In total, twenty young people with narcolepsy (age range $8-18$; mean: 13.5 years) participated in age-defined ( $8-13$ and $15-$ 17 years) mixed gender focus groups with two additional focus groups for parents. Narcolepsy onset was between one and two years prior to participation. The initial analysis produced seven themes with 135 items related to the concept of their HrQoL and submitted for review and thematic analysis by the a patient panel consisting of three representatives of the Swedish Narcolepsy Association; as a result, themes were clarified, questionnaire items were rewritten to improve understanding, and the number of items was reduced. Another part of the review process was a cognitive debriefing with 10 adolescents with narcolepsy attending the Agrenska center. The focus group methodology and analysis are presented in the focus group report (Additional file 1). At the end of the qualitative stage, a subset of 40 important and relevant items with good content validity were selected for inclusion in the pilot questionnaire. These 40 items comprised $27 \mathrm{HrQoL}$ questions, nine questions relating to the future, and four questions related to symptoms (Fig. 1). The cognitive debriefing exercise indicated that the questions were acceptable and understood as expected, but minor rewording was suggested. Neither the cognitive debriefing participants nor the patient panel considered any of the questions to be too difficult for the targeted age range. The themes were: Emotional support, School performance, Social image, Concern about the future, Being limited by the condition, Personal energy, and Disturbed sleep.

\section{Pilot test}

A total of 100 questionnaires were returned from patients with narcolepsy (59 girls) recruited from the Swedish Narcolepsy Association $(n=29)$, hospital outpatient clinics in the health care regions covering the west of Sweden $(n=38)$, and via a narcolepsy closedgroup Facebook page $(n=33)$ (Table 1$)$. The patients met the diagnostic criteria for narcolepsy according to ICSD-3 [33] . Narcolepsy type 1 was confirmed in 85\% of the patients. In the other patients, cataplexy was absent or cerebrospinal fluid hypocretin had not been measured.

The items were assessed for normality. Three items had a skewness value of greater than the prior set criterion value of 2.0 and were therefore rejected, resulting in a total of 15 items for the Psychosocial summary scale and six items for the Future outlook summary scale. The item reduction procedure is presented in Fig. 1.

\section{Factor structure}

Both principal components and principal axis factor analyses were conducted to discover the latent nature of the divisions in the HrQoL data. Three criteria were used to determine the number of factors: scree plot, eigenvalue, and percentage of variance explained by the factors. A minimum of four items loading higher than 0.5 within each factor was set as the criterion for a usable factor. A solution based on a fixed number of

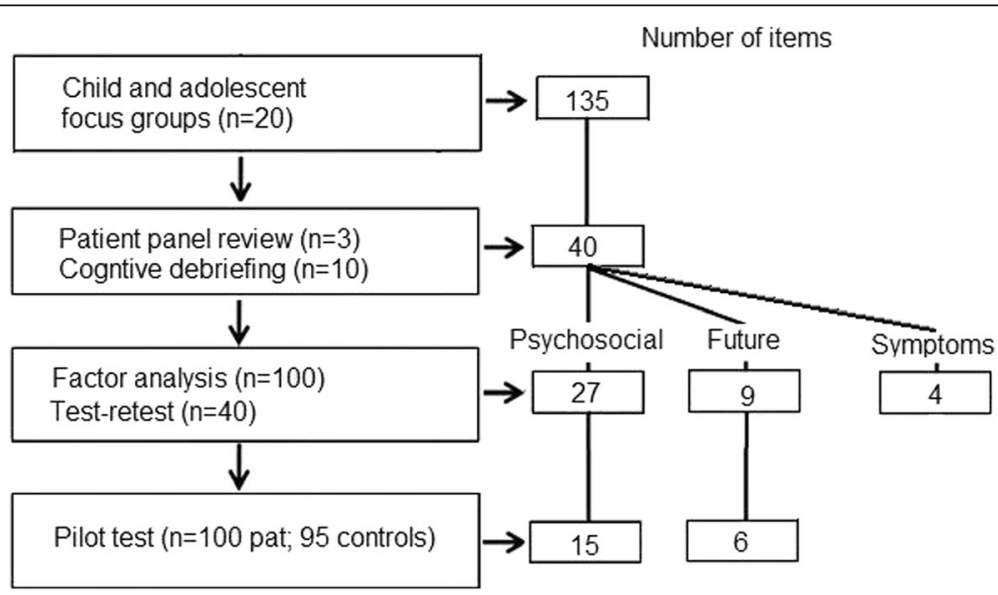

Fig. 1 Item reduction procedure 
Table 1 Demographic data on 100 patients with narcolepsy

\begin{tabular}{lll}
\hline Gender (\%) & Female & 59 \\
& Male & 41 \\
Age at onset (mean \pm SD) & $13.2 \pm 2.5$ \\
Age at diagnosis (mean \pm SD) & $14.5 \pm 3.2$ \\
Age at study (mean \pm SD) & $15.8 \pm 4.3$ \\
Symtoms & ESS score (mean \pm SD) & $13.0 \pm 4.4$ \\
& Cataplexy (\%) & 85 \\
& Hallucination (\%) & 52 \\
& Sleep paralysis (\%) & 43 \\
Treatment & Disturbed sleep (\%) & 86 \\
& Methylphenidate (\%) & 87 \\
& Modafinil (\%) & 21 \\
& Amphetamine (\%) & 7 \\
& Antidepressants (\%) & 21 \\
& Caffeine tablets (\%) & 7 \\
Sodium oxybate (\%) & 39 \\
\hline
\end{tabular}

Abbreviations: SD standard deviation, ESS Epworth Sleepiness Scale

ahypnagogic or hypnopompic hallucinations

factors was tested with different rotation solutions. A three-factor solution (Emotional, School/Concentration, and Social) gave the best description of the Psychosocial items and a two-factor solution (Expectations and Limitations) gave the best description for the Future outlook items. See Table 2 for the Psychosocial factor structure and Table 3 for the Future outlook factor structure.
Table 3 Future outlook factor structure

\begin{tabular}{lcc}
\hline & Factor structure & \\
\cline { 2 - 3 } Item titles & Future expectations & Future limitations \\
\hline Hopeful future & 0.990 & \\
Possibilities & 0.611 & \\
Problems in the future & 0.465 & 0.613 \\
After leaving school & & 0.593 \\
Travel & & 0.539 \\
Driving license & &
\end{tabular}

Extraction method: principal axis factoring

Rotation method: PROMAX with Kaiser normalization

The resulting questionnaire consisted of 21 items in two factors (Psychosocial, Future outlook) with five domains (Emotion, Social, School/Concentration, Expectations, Limitations). The patient panel in the review, and the adolescents with narcolepsy in the cognitive debriefing, considered that a questionnaire of 21 questions would not pose a significant burden, even on younger patients. The questions used in NARQoL-21 can be found in Additional file 2. A confirmatory factor analysis was conducted to assess the factor structure on the total population $(n=195)$. Maximum likelihood with estimated means and intercepts was used because of missing data. The chi square/degrees of freedom ratio was 2.03, which was less than the threshold of $3.0\left(\chi^{2}=176.4, \mathrm{df}=87, p<.001\right)$; the comparative fit index was 0.94 and the Tucker-Lewis index was 0.919 , both greater than the cut-off minimum

Table 2 Psychosocial factor structure

\begin{tabular}{|c|c|c|c|}
\hline \multirow[b]{2}{*}{ Item titles } & \multicolumn{3}{|l|}{ Factor structure } \\
\hline & Emotional reaction & School / Concentration & Social confidence \\
\hline Sadness & 0.771 & & \\
\hline Feeling alone & 0.717 & & \\
\hline Anger & 0.621 & & \\
\hline Anxiety & 0.602 & & \\
\hline Irritability & 0.537 & & \\
\hline Ability to concentrate & & 0.708 & \\
\hline Staying awake when watching TV & & 0.664 & \\
\hline Alertness & & 0.615 & \\
\hline Alertness in school & & 0.588 & \\
\hline Ability to follow lessons & & 0.577 & \\
\hline Staying awake on the bus & & 0.545 & \\
\hline Feeling confident & & & 0.607 \\
\hline Not giving up easily & & & 0.573 \\
\hline Getting on with others & & & 0.488 \\
\hline Feeling lazy & & & 0.469 \\
\hline
\end{tabular}

Extraction method: principal axis factoring 
value of 0.90 , thus indicating a reasonable-to-good model fit. The root mean square error of approximation was 0.073 ; and probability of close fit was 0.009 , indicating that the overall model fit between the hypothesized model and the data was moderate to good. Therefore, item factor loadings were considered satisfactory. See Fig. 2 for the confirmatory factor analysis path diagram.

A correlation analysis showed independence of the three HrQoL domains. The highest correlation was between Emotional reaction and Expectations for the future (0.629) (see Table 4).

Descriptive characteristics of the NARQoL-21 $(n=158)$ The NARQoL-21 mean transformed score was 58 (SD 16), Psychosocial 56 (SD 15.8), and Future outlook 64
(SD 22). The floor and ceiling results were acceptable, although the Limitations domain stood out from the others, with a ceiling of $18 \%$. The Cronbach's alpha value (indicating internal reliability) was 0.886 for the NARQoL-21, 0.832 for Psychosocial, and 0.798 for Future outlook. The lowest Cronbach's alpha value was found for the social domain (0.625) (Table 5). The response distribution was considered to be optimal.

\section{Test-retest reliability $(n=39)$}

A test-retest procedure was carried out on 40 respondents. One respondent did not complete the retest and was therefore excluded from the analysis. Due to the method of administration, follow-up of non-responders was not possible. According to the Swedish Narcolepsy

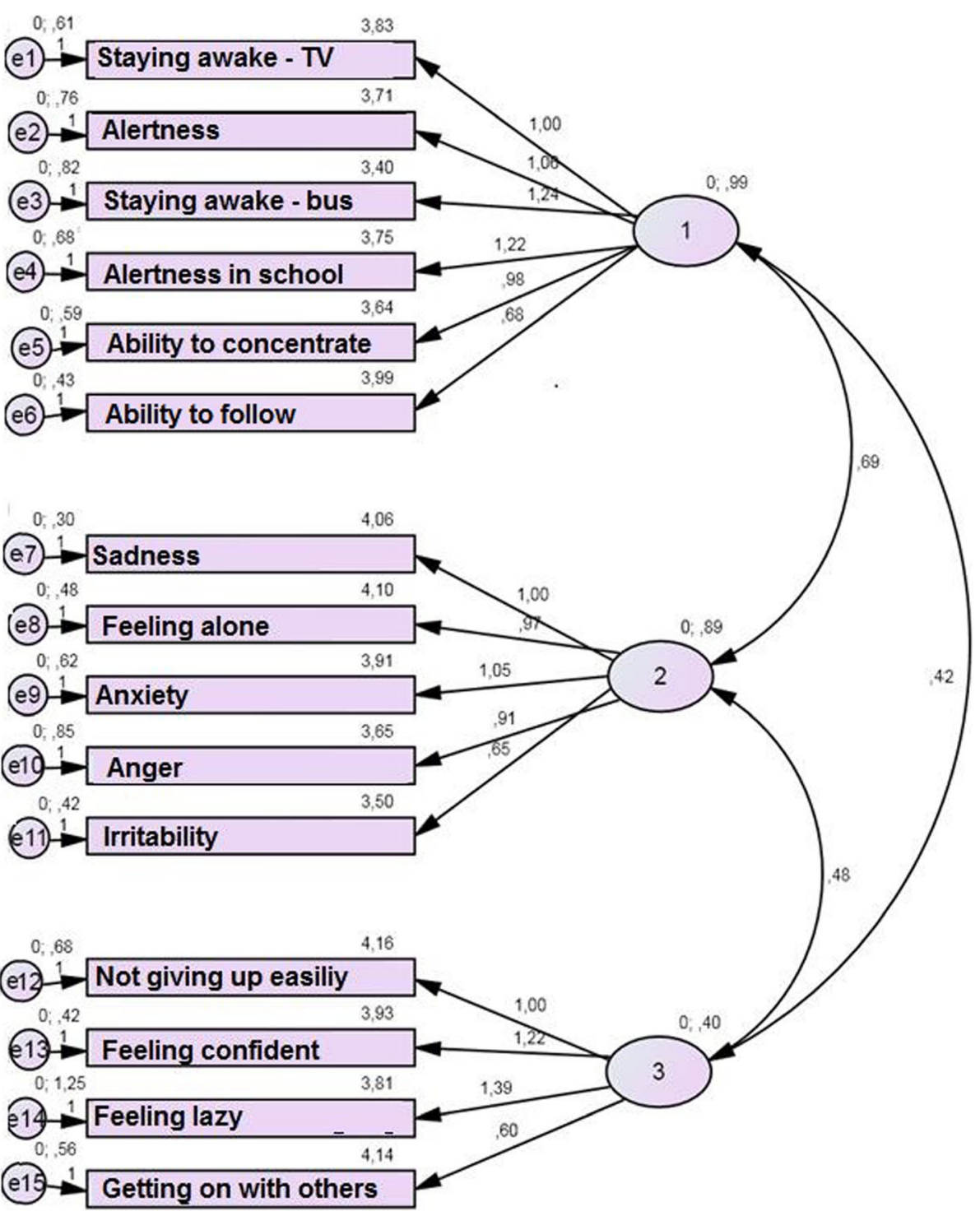

Fig. 2 Confirmatory factor analysis path diagram $(n=195)$ 
Table 4 Correlations between domains ( $n=100$ patients)

\begin{tabular}{|c|c|c|c|c|c|}
\hline & \multicolumn{3}{|l|}{ Psychosocial domains } & \multicolumn{2}{|c|}{ Future outlook domains } \\
\hline & Emotional reaction & Social confidence & School/ Concentration & Expectations & Limitations \\
\hline Emotional reaction & 1 & 0.461 & 0.388 & 0.629 & 0.448 \\
\hline Social confidence & & 1 & 0.242 & 0.512 & 0.429 \\
\hline School/ Concentration & & & 1 & 0.509 & 0.335 \\
\hline Expectations & & & & 1 & 0.515 \\
\hline Limitations & & & & & 1 \\
\hline
\end{tabular}

All correlations are significant at the 0.01 level

Association, no selection was made and no bias in responders was evident.

Questionnaires were returned within an average of 15 days. Three patients had missing data of less than $10 \%$, and these scores were imputed based on their individual range of scores. Mean \pm SD scores for the test and retest were $57.39 \pm 13.68$ and $61.11 \pm 14.04$, respectively (Table 6).

The ICCs (average measures) were good: NARQoL$21=0.933 \quad(95 \% \quad$ CI $\quad 0.873-0.965)$. The agreement between the measures was good to excellent with a similar standard error of the means.

\section{Floor and ceiling effects}

As shown in Table 5, there were generally no floor or ceiling effects. The exception is in the Limitation domain, where a ceiling effect of $18 \%$ was found. This indicates that caution must be taken when interpreting the scores of patients with a high score (lack of limitation) on this domain, due to reduced reliability at this end of the scale.

\section{Convergent validity - patients only $(n=92)$}

NARQoL-21 showed good convergent validity against the KIDSCREEN-10 index. A correlation of $\mathrm{rs}=0.769$ and ICC (average measures) of 0.706 (CI 0.555-0.806) were found, indicating good convergent validity. This means that the NARQoL-21 can be used as a satisfactory measure of $\mathrm{HrQoL}$ in this population.

Comparing the patient and control populations, it was found that NARQoL-21 had a larger range of scores than KIDSCREEN-10 and a closer approximation to a normal distribution in the patient population (Table 7). A Bland-Altman plot (Fig. 3) shows that, despite the good correlation between the measures and the fact that $97.5 \%$ of the values were within the $95 \%$ confidence intervals (limits of agreement), there was proportional bias. This is shown by the scatter of difference values increasing progressively as the average values of the tests increase. This proportional bias can mostly be eliminated by log transformation of the raw values as recommended by Bland and Altman [34]; however, the bias was still not fully eliminated. As expected, the control subjects were mostly at the higher end of the HrQoL scale and it is here that the greatest variation between the tests was observed.

\section{Discriminant validity}

Discriminant validity was tested with known-group analysis on narcolepsy patients versus matched healthy controls, using a Mann-Whitney $U$ test to determine whether the distribution of $\mathrm{HrQoL}$ in the two groups differed significantly $\left(U=405.5, n_{1}=n_{2}=158, P<0.001\right.$ two-tailed) with an effect size of $\mathrm{d}=2.114$ indicating a

Table 5 Characteristics of the NARQoL-21 scales in the study sample

\begin{tabular}{|c|c|c|c|c|c|c|}
\hline \multirow[b]{2}{*}{ Scale (no. of items) } & \multicolumn{4}{|c|}{$\begin{array}{l}\text { Patient group } n=79 \\
\text { (mean age } 14 \mathrm{yrs} \text { ) }\end{array}$} & \multirow{2}{*}{$\begin{array}{l}\text { Control group } n=79 \text { (mean age } 12 \text { yrs) } \\
\text { Mean (SD) }\end{array}$} & \multirow{2}{*}{$\begin{array}{l}\text { Total sample } n=158 \\
\text { alpha }\end{array}$} \\
\hline & Mean (SD) & $\%$ floor & $\%$ ceiling & alpha & & \\
\hline HrQoL (21) & $58.2(16.3)$ & 0 & 0 & 0.886 & $88.1(9.8)$ & 0.938 \\
\hline Psychosocial (15) & $55.9(15.8)$ & 0 & 0 & 0.839 & $86.8(11.1)$ & 0.916 \\
\hline Future outlook (6) & $64.0(21.8)$ & 0 & 2 & 0.776 & $91.1(9.0)$ & 0.832 \\
\hline Emotional reaction (5) & $58.3(22.7)$ & 0 & 0 & 0.826 & $85.3(13.5)$ & 0.861 \\
\hline Social confidence (4) & $66.8(19.7)$ & 0 & 4 & 0.638 & $83.4(16.0)$ & 0.695 \\
\hline School/Concentration (6) & $46.8(20.1)$ & 0 & 0 & 0.761 & $90.4(9.8)$ & 0.888 \\
\hline Expectations (3) & $55.8(25.0)$ & 0 & 6 & 0.786 & $87.5(13.6)$ & 0.837 \\
\hline Limitations (3) & $72.3(24.9)$ & 1 & 18 & 0.629 & $94.8(10.0)$ & 0.669 \\
\hline
\end{tabular}


Table 6 Test-retest results with intraclass correlation coefficients (ICC)

\begin{tabular}{lllll}
\hline N=39 & Mean (SD) & Min & Max & ICC (95\%Cl) \\
\hline NARQoL-21_1 (test) & $60(14)$ & 33 & 100 & $0.928(0.858-0.963)$ \\
NARQoL-21_2 (retest) & $62(15)$ & 29 & 100 & \\
Emotion_1 & $61(19)$ & 20 & 90 & $0.833(.776-.938)$ \\
Emotion_2 & $63(20)$ & 10 & 95 & \\
Social_1 & $69(19)$ & 19 & 100 & $0.869(.751-.931)$ \\
Social_2 & $72(18)$ & 25 & 100 & \\
School_1 & $47(18)$ & 17 & 92 & $0.924(.855-.960)$ \\
School_2 & $52(18)$ & 21 & 96 & \\
Expectations_1 & $59(25)$ & 8 & 100 & $0.906(.822-.951)$ \\
Expectations_2 & $59(24)$ & 8 & 100 & \\
Limitations_1 & $74(22)$ & 17 & 100 & $0.926(.859-.961)$ \\
Limitations_2 & $72(24)$ & 17 & 100 & \\
\hline
\end{tabular}

significant difference between the control and patient populations (Table 8).

\section{Sensitivity of the NARQoL-21}

A ROC curve was calculated to identify the relative sensitivity of the new HrQoL instrument (NARQoL21) against the comparison instrument (KIDSCREEN10). The AUC for the NARQoL-21 was 0.939 (CI 0.903-0.975), for the Psychosocial factor it was 0.940 (CI 0.904-0.976) and for the Future outlook factor 0.886 (CI 0.833-0.938). The AUC for KIDSCREEN-10 was 0.876 (CI 0.821-0.932) (Fig. 4).

Both instruments demonstrated excellent or good sensitivity and specificity; however, the NARQoL-21 had better discrimination of healthy controls. A z-score test showed a significant difference between the AUC for the two instruments $(p=0.038)$.

Interpretability of scores - A clinical cut-off for intervention The NARQoL-21 reached acceptable levels of reliability (>0.9) for individual assessment [24] and therefore the estimation of cut-off scores may be appropriate. Cut-off values for suboptimal HrQoL can also be identified via the ROC curve. Using the cut-off value of $<38$ provided by the developers of KIDSCREEN [19], adolescents were classified as having an optimal HrQoL score if it was above the cut-off point and a suboptimal score if it was below the cut-off point. In our population 19 had suboptimal HrQoL according to the KIDSCREEN-10 cut-off, all 19 were from the patient population. An equivalent cut-off score was selected that maximized the sum of sensitivity and specificity. A NARQoL-21 score of $<42$ would identify individuals with suboptimal HrQoL with a sensitivity of $84 \%$, which corresponds to high negative predictive value, and specificity of $92 \%$, which gives high specificity corresponding to high positive predictive value, thus having an acceptable likelihood of a false positive result (Table 9 in Additional file 3). At this cut-off, NARQoL-21 would be considered as having high sensitivity [35].

\section{Discussion}

To our knowledge, the NARQoL-21 represents the first disease-specific HrQoL instrument for use in children and adolescents with narcolepsy. The NARQoL-21 is a brief questionnaire with two factors, five domains, and 21 items, which can be used as a tool to assess the patient-reported outcomes of narcolepsy treatment. The two factors are Psychosocial (15 items) and Future outlook (6 items). The NARQoL-21 is not limited by floor or ceiling effects, which means that the instrument does not limit the range of data that can be reported within this population. The item list was developed from the expressed views of children and adolescents with narcolepsy, aged 8-18 years. The final pilot questionnaire was refined on the basis of patient panel discussions with representatives of the Swedish Narcolepsy Association and on psychometric analysis. It is relatively short and has acceptable patient burden. A score of $<42$ was selected as a cut-off score that maximized the sum of sensitivity and specificity. The NARQoL-21 provides a good discriminatory power and it is a valid and well-tested, stable, child-centred, self-report measure for children and adolescents with narcolepsy.

The questionnaire differs from many instruments measuring HrQoL by the inclusion of two domains related to future expectations and limitations. The focus groups produced an image of the young people's attitudes to their condition which went beyond the traditional model of HrQoL and included aspects of concern for the long-term future (see Additional file 1). These

Table 7 Matched sample comparison of psychometric characteristics

\begin{tabular}{|c|c|c|c|c|c|c|}
\hline Matched samples $n=79 / 79$ & Mean age; gender & & Min-Max & Mean (SD) & Skewness & Kurtosis \\
\hline \multirow[t]{2}{*}{ Patient group } & \multirow{2}{*}{$\begin{array}{l}14 \text { yrs:; } \\
39 \text { male } \\
40 \text { female }\end{array}$} & NARQOL-21 & $20-92$ & $60(16)$ & -0.108 & -0.677 \\
\hline & & KIDSCREEN-10 & $29-63$ & $43(7.2)$ & 0.484 & 0.004 \\
\hline \multirow[t]{2}{*}{ Control group } & \multirow{2}{*}{$\begin{array}{l}12 \text { yrs.; } \\
39 \text { male } \\
40 \text { female }\end{array}$} & NARQoL-21 & $51-100$ & $88(10)$ & -1.603 & 2.975 \\
\hline & & KIDSCREEN-10 & $38-84$ & $56(10)$ & 1.180 & 1.165 \\
\hline
\end{tabular}




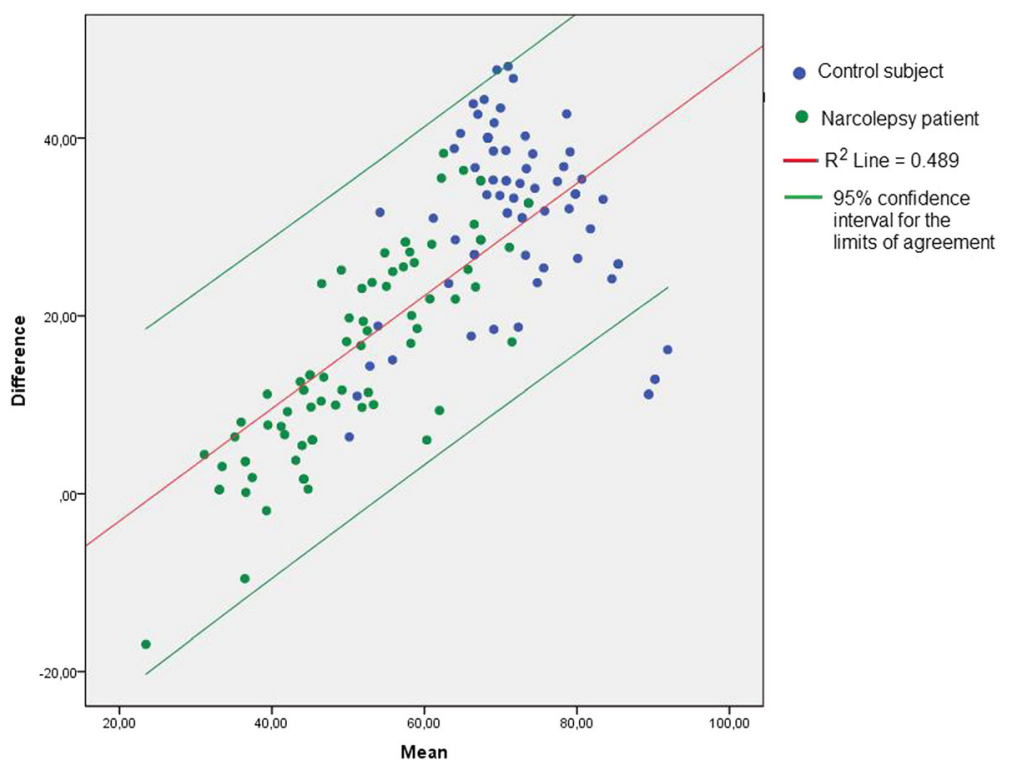

Fig. 3 Bland-Altman plot showing differences between the NARQOL-21 and KIDSCREEN-10 tests

issues demonstrate a strong sense that these young people feel that they will miss out on what could be called a 'good life'. This is not an entirely unique idea within HrQoL research, although concerns about the future are not normally included as domains in HrQoL measurement. The idea of including future outlook in an assessment of HrQoL has been explored by others [36, 37]. Raphael et al. [36] categorized HrQoL into three areas: being (the basic aspects of who the person is), belonging (the person's fit with his or her environment), and becoming (the purposeful activities carried out to achieve personal goals, hopes, and wishes) [38, 39]. In our model, being and belonging come within the concept of the Psychosocial domains (Emotional, Social, and School/Concentration) whereas the becoming concept is captured by the two Future outlook domains (Expectations and Limitations). Future outlook is clearly an important consideration for children and adolescents.

Even patients with a relatively low burden of narcolepsy can experience a decrease in their HrQoL due to the occupational, career, and social effects of narcolepsy [40]. This highlights the need for a condition-specific

Table 8 Discriminant validity using known groups (healthy controls vs narcolepsy patients)

\begin{tabular}{|c|c|c|c|c|c|}
\hline Scale (no. of items) & & Mean (SD) & Min-max & $P$ value & Cohen's o \\
\hline \multirow[t]{2}{*}{ HrQoL (21) } & Patient & $59(10)$ & $20-92$ & & \\
\hline & Control & $88(10)$ & $51-100$ & $<0.001$ & 2.114 \\
\hline \multirow[t]{2}{*}{ Psychosocial (15) } & Patient & $58(16)$ & $15-90$ & & \\
\hline & Control & $87(11)$ & $42-100$ & $<0.001$ & 2.253 \\
\hline \multirow[t]{2}{*}{ Future outlook (6) } & Patient & $65(21)$ & $13-100$ & & \\
\hline & Control & $91(9)$ & $67-100$ & $<0.001$ & 1.641 \\
\hline \multirow[t]{2}{*}{ Emotional reaction (5) } & Patient & $61(23)$ & $5-95$ & & \\
\hline & Control & $85(14)$ & $25-100$ & $<0.001$ & 1.288 \\
\hline \multirow[t]{2}{*}{ Social confidence (4) } & Patient & $67(20)$ & $13-100$ & & \\
\hline & Control & $83(16)$ & $31-100$ & $<0.001$ & 0.892 \\
\hline \multirow[t]{2}{*}{ School/Concentration (6) } & Patient & 49 (19) & $17-88$ & & \\
\hline & Control & $90(10)$ & $58-100$ & $<0.001$ & 2.774 \\
\hline \multirow[t]{2}{*}{ Expectations (3) } & Patient & $57(25)$ & $8-100$ & & \\
\hline & Control & $88(14)$ & $33-100$ & $<0.001$ & 1.503 \\
\hline \multirow[t]{2}{*}{ Limitations (3) } & Patient & $73(23)$ & $17-100$ & & \\
\hline & Control & 95 (10) & 58-100 & $<0.001$ & 1.243 \\
\hline
\end{tabular}




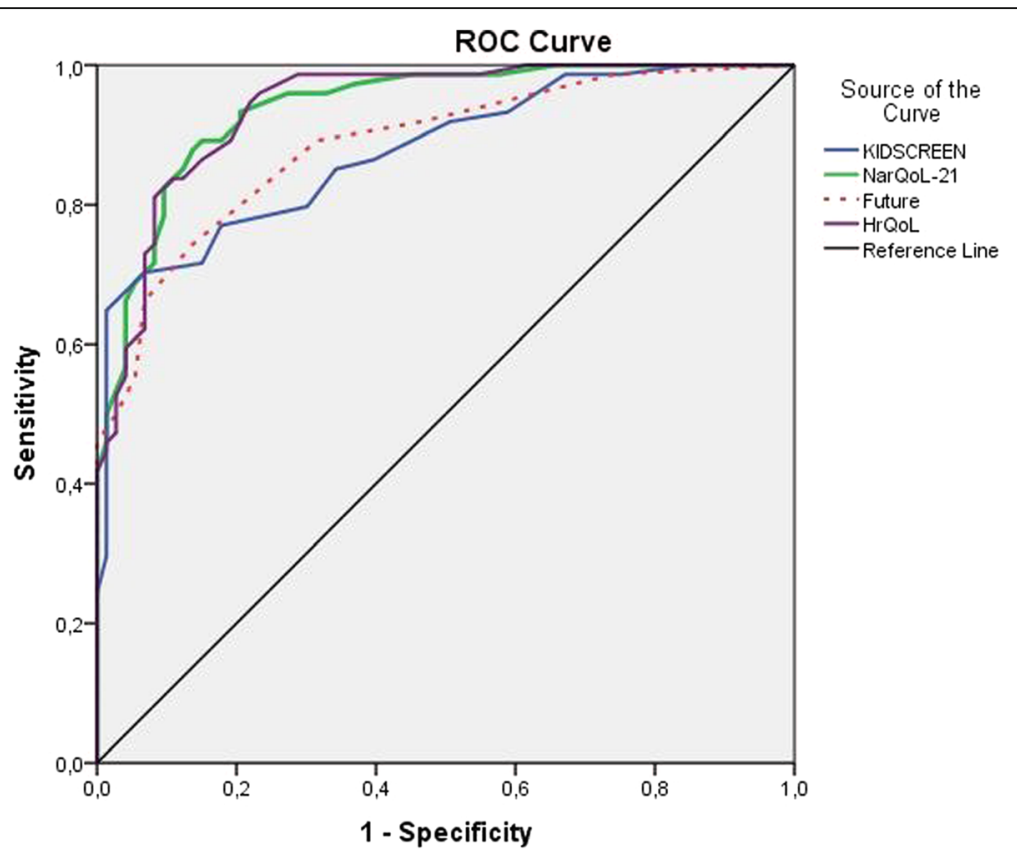

Fig. 4 ROC curve comparing NARQOL-21 and KIDSCREEN-10 $(n=158)$

measure that can identify outcomes from the perspective of the children themselves [41]. There have been very few HrQoL studies on children and adolescents with narcolepsy, and those that have been carried out have so far used generic instruments. For example: Stores et al. [14] used the parent version of the Child Health Questionnaire (age range 5-17 years; 50-items; 13 domains including two domains covering limitations in schoolwork and activities with friends [42]; Inocente et al. [43] and Lecendreux [44] used the self-report version of the Experience and Perceived Health in Adolescents instrument (Vécu et Santé Perçue de l'Adolescent, VSP-A, age range 11-17 years; 39 items; 7 domains, including school life and future) [37]; Rocco et al. [11] used the self-report version of the Pediatric Quality of Life Inventory (PedsQL 4.0, age range 5-18 years; 23 items, 4 domains: physical, social, emotional and school functioning) [45]. All of these instruments are generic HrQoL instruments. The PedsQL 4.0 has a domain structure similar to NARQoL-21, with physical, emotional, social and school functioning, and the VSP-A has a future domain similar to NARQoL-21, however neither of these instruments are condition specific. Results derived from the NARQoL-21 can be used to analyze which aspects of disease have the strongest effect on the patient. We would suggest that this will better facilitate the provision of personalized care and increase patient satisfaction.

Some limitations of the study should be recognized. Firstly, the study sample was relatively small, as is inevitable when working with rare-condition populations. A single study of this kind can only provide limited support towards establishing reliability or validity. Secondly, in relation to the challenge above, we prioritized inclusion in order to increase the number of participants in the study but, due to the practicalities of access to patient and control subjects, it was not possible to match the control group by age exactly to the patient group; however, by excluding the oldest 21 patients from the patient group, a substantial subset of the participants could be matched adequately for the analyses described here. There is still a difference in age, although we do not believe that this will affect the analyses carried out. Thirdly, the heterogeneity of the patient population, having been drawn from several different sources, and the fact that this is a cross-sectional study, will limit the inferences that can be drawn. Nonetheless, it can be deduced that there is substantial evidence of reasonable convergent validity with the generic instrument (KIDSCREEN-10) and that the NARQoL-21 could be used to assess young narcolepsy patients' subjective QoL. The true responsiveness of the instrument can only be assessed following a longitudinal study (internal responsiveness) or in relation to an intervention or change (external responsiveness) [31].

We also recognize that, because we have developed the instrument in one country and in a Swedishspeaking population, it needs to be translated and validated in other languages in order to facilitate the greatest usage. The English translation is ready for validation and we would also welcome other translations, which would allow for pooling of data over larger and more diverse groups. 


\section{Conclusion}

There is a general need for enhanced efforts in the field of HrQoL research in all rare diseases. Overall, there is a need for more longitudinal follow-up studies, where health-related quality of life can be addressed. The NARQoL-21 child-centred, self-report measure, which has good discrimination and convergent validity, and excellent internal and external reliability, will prove to provide precise and stable measurement and be a useful addition to the instruments that can be used to evaluate the effects of narcolepsy in a child and adolescent population in longitudinal follow-up. Its inclusion in clinical data registries would be an important step forward to a better understanding of young people's experience of this health condition.

\section{Additional files}

Additional file 1: Focus Group Summary. (PDF 185 kb)

Additional file 2: NARQOL-21 English-Swedish translation. (PDF 20 kb)

Additional file 3: Table 9. NARQoL-21 cut-off scores for differentiating between optimal and suboptimal HrQoL. (PDF $229 \mathrm{~kb}$ )

\section{Abbreviations}

ADHD: Attention deficit hyperactivity disorder;" AUC: Area under the curve; Cl: Confidence interval; HrQoL: Health-related quality of life; ICC: Intraclass Correlation Coefficient; KIDSCREEN: A set of generic quality-of-life instruments for children; KIDSCREEN-10: the KIDSCREEN Mental Health Index for children; NARQoL-21: Narcolepsy quality-of-life instrument with 21 questions; ROC: Receiver operating characteristic; SD: Standard deviation

\section{Acknowledgments}

The authors would like to thank the focus group participants who shared their experiences and thoughts with us. We are grateful to Ågrenska National Competence Centre for Rare Diseases for allowing us to participate in their Narcolepsy family weeks and talk to the participants. We are also grateful for the support of the Swedish Narcolepsy Association (Narkolepsiföreningen) for sending the questionnaire to their members. We thank Jannie Nilsson MD for invaluable help with data management, Sarah Hitz MSc from Dept. of Health Science, Faculty of Life Sciences, Hamburg University of Applied Sciences, Hamburg, Germany for help with the focus group content analysis and CMC Scientific English (scientificenglish.se) for help with proofreading this manuscript.

\section{Availability of data and materials}

For reasons of confidentiality, the datasets generated and analyzed during the current study are not publicly available but they are available from the corresponding author upon reasonable request.

\section{Funding}

Funding was obtained from ALF grants, Region Västra Götaland, Ahlqvist's Foundation, and Health Region Halland, Sweden (FF-2012-009). The funding bodies had no role in the design of the study or collection, analysis, and interpretation of data, and they did not contribute to the writing of the manuscript.

\section{Authors' contributions}

JC carried out the focus group interviews and data analysis and drafted the manuscript. AS contacted the patient groups, administered the questionnaire, participated in the analysis, and jointly drafted the manuscript. TH \& ND participated in the design and coordination of the study and helped to draft the manuscript. All authors read and approved the final manuscript.

\section{Ethics approval and consent to participate}

Ethical approval for the study procedures was given by the Regional Board of Medical Ethics at the University of Gothenburg (ref: 246-11). All patients, control subjects, and their parents received a letter with information about the study and all consented to participation. All procedures were in accordance with the Helsinki Declaration as revised in 2013.

\section{Consent for publication}

Not applicable.

\section{Competing interests}

The authors declare that they have no competing interests.

\section{Publisher's Note}

Springer Nature remains neutral with regard to jurisdictional claims in published maps and institutional affiliations.

\section{Author details}

${ }^{1}$ Department of Pediatrics, Institute of Clinical Sciences, Sahlgrenska Academy at University of Gothenburg, Gothenburg, Sweden. ${ }^{2}$ Department of Pediatrics, Halland Hospital, Halmstad, Sweden.

Received: 17 August 2016 Accepted: 21 June 2017

Published online: 04 July 2017

References

1. Overeem $S$, van Nues SJ, van der Zande WL, Donjacour CE, van Mierlo P, Lammers GJ. The clinical features of cataplexy: a questionnaire study in narcolepsy patients with and without hypocretin-1 deficiency. Sleep Med. 2011;12:12-8.

2. Aran A, Einen M, Lin L, Plazzi G, Nishino S, Mignot E. Clinical and therapeutic aspects of childhood narcolepsy-cataplexy: a retrospective study of 51 children. Sleep. 2010;33:1457-64.

3. Morandin M, Bruck D. Understanding automatic Behavour in narcolepsy: new insights using a phenomenological approach. Open Sleep J. 2013;6:1-7.

4. Silber MH, Krahn LE, Olson EJ, Pankratz VS. The epidemiology of narcolepsy in Olmsted County, Minnesota: a population-based study. Sleep. 2002;25: 197-202.

5. Wing YK, Li RH, Lam CW, Ho CK, Fong SY, Leung T. The prevalence of narcolepsy among Chinese in Hong Kong. Ann Neurol. 2002;51:578-84.

6. Dauvilliers Y, Montplaisir J, Molinari N, Carlander B, Ondze B, Besset A, et al. Age at onset of narcolepsy in two large populations of patients in France and Quebec. Neurology. 2001:57:2029-33.

7. De la Herran-Arita AK, Guerra-Crespo M, Drucker-Colin R. Narcolepsy and orexins: an example of progress in sleep research. Front Neurol. 2011;2:26.

8. Dorris L, Zuberi SM, Scott N, Moffat C, McArthur I. Psychosocial and intellectual functioning in childhood narcolepsy. Dev Neurorehabil. 2008;11:187-94.

9. Szakacs A, Hallbook T, Tideman P, Darin N, Wentz E. Psychiatric comorbidity and cognitive profile in children with narcolepsy with or without association to the H1N1 influenza vaccination. Sleep. 2015;38:615-21.

10. Inocente CO, Gustin MP, Lavault S, Guignard-Perret A, Raoux A, Christol N, et al. Quality of life in children with narcolepsy. CNS Neurosci Ther. 2014;20:763-71.

11. Rocca FL, Finotti E, Pizza F, Ingravallo F, Gatta M, Bruni O, et al. Psychosocial profile and quality of life in children with type 1 narcolepsy: a case-control study. Sleep. 2016;39:1389-98.

12. Ervik S, Abdelnoor M, Heier MS, Ramberg M, Strand G. Health-related quality of life in narcolepsy. Acta Neurol Scand. 2006;114:198-204.

13. Jennum P, Ibsen R, Petersen ER, Knudsen S, Kjellberg J. Health, social, and economic consequences of narcolepsy: a controlled national study evaluating the societal effect on patients and their partners. Sleep Med. 2012;13:1086-93.

14. Stores $G$, Montgomery P, Wiggs L. The psychosocial problems of children with narcolepsy and those with excessive daytime sleepiness of uncertain origin. Pediatrics. 2006;118:e1116-23.

15. Patrick DL, Deyo RA. Generic and disease-specific measures in assessing health status and quality of life. Med Care. 1989;27:S217-32.

16. Chaplin JE, Crawley FP, Sanna L, Ceci A, Neubauer D, Giaquinto C, et al. RESPECT patient needs. Lengerich: Pabst Science; 2012.

17. Chaplin JE: DISABKIDS Focus Group Manual. vol. April 2017, 4 edition. pp. Outline of the focus group procedure used in DISABKIDS and subsequent 
projects. Gothenburg, Sweden: University of Gothenburg; 2015:Outline of the focus group procedure used in DISABKIDS and subsequent projects.

18. Baars R, Chaplin JE, Koopman HM, and the DISABKIDS group: A child focus group methodology: experiences from the European DISABKIDS project. In Paediatric Health Related Quality of Life: a European Perspective Instrument development, validation, and use in clinical practice. Leiden: Leiden University Open Access.

19. Ravens-Sieberer U, et al. \& the European KIDSCREEN Group. : The KIDSCREEN questionnaires-Quality of life questionnaires for children and adolescents—Handbook. Pabst Science Publisher, Lengerich 2006.

20. Ravens-Sieberer U, Erhart M, Rajmil L, Herdman M, Auquier P, Bruil J, et al. Reliability, construct and criterion validity of the KIDSCREEN-10 score: a short measure for children and adolescents' well-being and health-related quality of life. Qual Life Res. 2010;19:1487-500.

21. McHorney CA, Tarlov AR. Individual-patient monitoring in clinical practice: are available health status surveys adequate? Qual Life Res. 1995;4:293-307.

22. Brown TA. Confirmatory factor analysis for applied research. New York: Guilford Press; 2006.

23. Wu S, Crespi CM, Wong WK. Comparison of methods for estimating the intraclass correlation coefficient for binary responses in cancer prevention cluster randomized trials. Contemp Clin Trials. 2012;33:869-80.

24. Terwee CB, Bot SD, de Boer MR, van der Windt DA, Knol DL, Dekker J, et al. Quality criteria were proposed for measurement properties of health status questionnaires. J Clin Epidemiol. 2007;60:34-42.

25. Ravens-Sieberer U, Auquier P, Erhart M, Gosch A, Rajmil L, Bruil J, et al. The KIDSCREEN-27 quality of life measure for children and adolescents: psychometric results from a cross-cultural survey in 13 European countries. Qual Life Res. 2007;16:1347-56.

26. Bland JM, Altman DG. Statistical methods for assessing agreement between two methods of clinical measurement. Lancet. 1986;1:307-10.

27. Fayers PM, Machin D: Quality of Life: the Assessment, Analysis and Interpretation of Patient-Reported Outcomes In. 2nd edition. Chichester, West Sussex, UK: : John Wiley \& Sons, Ltd.; 2007

28. Cohen J. A power primer. Psychol Bull. 1992;112:155-9.

29. Becker Effect Size Calculator [http://www.uccs.edu/ /becker/]. Accessed 24 June 2017

30. Stucki G, Liang MH, Fossel AH, Katz JN. Relative responsiveness of conditionspecific and generic health status measures in degenerative lumbar spinal stenosis. J Clin Epidemiol. 1995;48:1369-78.

31. Husted JA, Cook RJ, Farewell VT, Gladman DD. Methods for assessing responsiveness: a critical review and recommendations. J Clin Epidemiol. 2000;53:459-68.

32. Hanley JA, McNeil BJ. The meaning and use of the area under a receiver operating characteristic (ROC) curve. Radiology. 1982;143:29-36.

33. American Academy of Sleep Medicine. International Classification of Sleep Disorders - Third Edition (ICSD-3) (2014) Darien, IL American Academy of Sleep Medicine.

34. Bland JM, Altman DG. Measuring agreement in method comparison studies. Stat Methods Med Res. 1999:8:135-60.

35. Altman DG, Bland JM. Diagnostic tests. 1: sensitivity and specificity. BMJ. 1994;308:1552.

36. Raphael D, Rukholm E, Brown I, Hill-Bailey P, Donato E. The quality of life profile-adolescent version: background, description, and initial validation. J Adolesc Health. 1996;19:366-75.

37. Simeoni MC, Sapin C, Antoniotti S, Auquier P. Health-related quality of life reported by French adolescents: a predictive approach of health status? J Adolesc Health. 2001;28:288-94

38. Chaplin JE. Growth-related quality of life. Horm Res Paediatr. 2011;76 (Suppl 3):51-2

39. Renwick R, Brown I: Being, belonging, becoming: the Centre for Health Promotion model of quality of life. In Quality of life in healt h promotion and rehabilitation: conceptual approaches, issues, and applications Edited by Renwick RB, I., \& M. Nagler. Thousand Oaks, CA: Sage; 1996: 88

40. Dodel R, Peter H, Spottke A, Noelker C, Althaus A, Siebert U, et al. Healthrelated quality of life in patients with narcolepsy. Sleep Med. 2007;8:733-41.

41. Bogan R, Swick T, Mamelak M, Kovacevic-Ristanovic R, Lai C, Black J, et al. Evaluation of quality of life in patients with narcolepsy treated with sodium Oxybate: use of the 36-item short-form health survey in a clinical trial. Neurol Ther. 2016;5:203-13.

42. Landgraf JM, Maunsell E, Speechley KN, Bullinger M, Campbell S, Abetz L, et al. Canadian-French, German and UK versions of the child health questionnaire: methodology and preliminary item scaling results. Qual Life Res. 1998;7:433-45.

43. Inocente CO, Gustin MP, Lavault S, Guignard-Perret A, Raoux A, Christol N, et al. Depressive feelings in children with narcolepsy. Sleep Med. 2014;15:309-14.

44. Lecendreux M, Lavault S, Lopez R, Inocente CO, Konofal E, Cortese S, et al. Attention-deficit/hyperactivity disorder (ADHD) symptoms in Pediatric narcolepsy: a cross-sectional study. Sleep. 2015;38:1285-95.

45. Varni JW, Seid M, Kurtin PS. PedsQL 4.0: reliability and validity of the Pediatric quality of life inventory version 4.0 generic core scales in healthy and patient populations. Med Care. 2001;39:800-12.

\section{Submit your next manuscript to BioMed Central and we will help you at every step:}

- We accept pre-submission inquiries

- Our selector tool helps you to find the most relevant journal

- We provide round the clock customer support

- Convenient online submission

- Thorough peer review

- Inclusion in PubMed and all major indexing services

- Maximum visibility for your research

Submit your manuscript at www.biomedcentral.com/submit
Biomed Central 